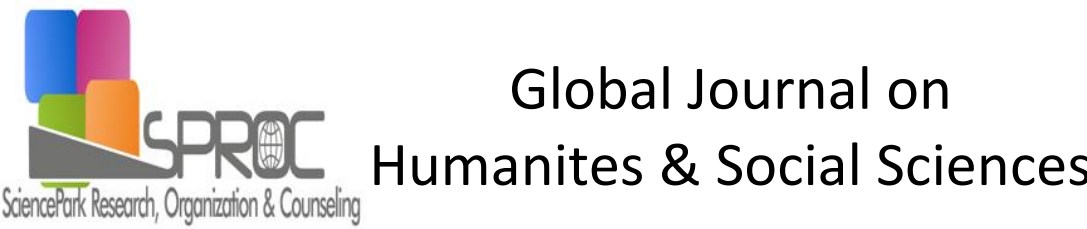

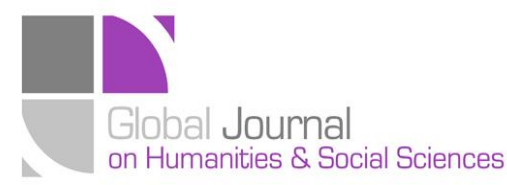

Vol 3 (2016) 96-100

Selected Paper of 4th World Conference on Design and Arts, (DAE-2015)

26-28 June 2015, St.Petersburg Christan University, St. Petersburg, Russia.

\section{Contribution of mental training to the improvement of sports performance}

\author{
Grosu Vlad Teodor*, Technical University, Muncii Street 103-105, Cluj - Napoca, 400641, Romania \\ Moraru Cristina Elena, "Al.I.Cuza" University, Carol Street 11, lasi, 700506, Romania \\ Grosu Emilia Florina, "Babeș - Bolyai" Universiy, M. Kogalniceanu Street 1, Cluj - Napoca, 400084, Romania \\ Preja Carmen Aneta, University Center North of Baia Mare , Victoriei Street 76, Baia Mare, 430122, Romania
}

\section{Suggested Citation:}

Grosu, V.T., Moraru, C.E., Grosu E.F., \& Preja C.A. (2016). Contribution of mental training to the improvement of sports performance, Global Journal on Humanites \& Social Sciences. [Online]. 03, pp 96-100. Available from: http://sproc.org/ojs/index.php/pntsbs

Received January 06, 2015; revised February 09, 2015; accepted April 23, 2015.

Selection and peer review under responsibility of Prof. Dr. Milan Matijevic.

(C)2016 SciencePark Research, Organization \& Counseling. All rights reserved.

\begin{abstract}
The aim of this study was to assess the influence of mental training on the increase in attention and manual response in certain athletes (skiers). The subjects within are samples are aged $12 \pm 5$ and $16 \pm 1$. The athletes who participated in this study are part of ski groups within School sports clubs. The experimental group comprises athletes from Gheorgheni, Baia-Sprie, while the control group includes of athletes from Topliţa, Sibiu, Predeal and Sinaia. We applied the ACRM (focused attention with manual response) test, because it provides information on the ability of remaining focused during activities with imposed pace and with dynamic field of observations. We conducted these tests after applying certain mental training techniques in the experimental group and after comparing the scores with those obtained by the control group. For the analysis, we used the SPSS 15.0 software. For the comparison of means between the groups of subjects, we applied ANOVA for the VP, EP and EX posttest measurements. The purpose was to determine whether the two groups have similar scores before the intervention. We applied mental imagery techniques on certain components of alpine skiing technique, based on hand-eye coordination. We also calculated a t test for dependent samples for VP, EP and $E X$, in posttest, to the end of establishing whether the intervention led to any alterations. The means and standard deviation for VP are as follows: for the control group 10.00 \pm 6.04 and for the experimental group 4.04 \pm 3.85 ; for EP test, the values for control group are 18.54 \pm 9.12 and for the experimental group 9.83 \pm 4.40 ; EX - the values obtained for the control group $0.86 \pm 0.07$ and for the experimental group $0.92 \pm 0.05$. The values for ( $t$ ) Student Test were the following: for VP $t=4.074, p<0.000$; EP $t=4.203, p<0.000$; $E X t=3.279, p<0.002$. Considering both the comparative analysis of scores to the tests.
\end{abstract}

* ADDRESS FOR CORRESPONDENCE: Cristina-Elena, Moraru, "Al.I.Cuza" University, Carol Street 11, lasi, 700506, Romania. E-mail address: gimcristinamoraru@yahoo.com / Tel.: +0-074-493-3133 
Grosu, V.T., Moraru, C.E., Grosu E.F., \& Preja C.A. (2016). Contribution of mental training to the improvement of sports performance, Global Journal on Humanites \& Social Sciences. [Online]. 03, pp 96-100. Available from: http://sproc.org/ojs/index.php/pntsbs

Keywords: attention, skiing, mental training, manual response

\section{Introduction}

Anticipation, also known as windup - release, is a technique used mostly in linked, short radius turns. Although inklings of the movement pattern can be seen in pictures of skiers from the 1950s and earlier, anticipation became commonly visible in the skiing of world-class ski racers in the mid-1960s. To this day, it remains a fundamental element of advanced short-turn technique (LeMaster, 2011).

In skiers, it is important to respect the following technical aspects, suggested by Warren, S. (2006, p. 99), with regards to practising pole-planting - wrist movement. A strong pole - plant comes from a small flick of the wrist - the movement does not come from swinging the arms. Standing still, practice, moving the pole backwards and forwards with the wrist only. When it feels right, try the exercise while skiing. In the following lines, we will explain the importance of hand and arm position. One of the most common technical errors in skiing is dropping the inside hand, which pulls the skier's balance away from the outside ski. Another common problem, raising the outside hand, usually has some effect. Watch the inside hands of World Cup skiers, particularly in the toughest turns. The inside hand is at least as high as the outside hand, and reaching in the same direction. The best skiers in the world strive for quiet, level arms. Those whose arm discipline is less than perfect usually admit that they would ski better if their arms did not move around so much. Limiting arm movement is of the basic training of all great skiers, who at some point in their lives have done countless drills to develop quiet, balanced hands. Try to keep your inside hand in your field of view at all times. Better still, work to keep both, hands at the same level, with forearms parallel to snow. Avoid the common problem of reaching forward with your downhill hand to plant your pole when your inside hand drops.

Doing so pulls your downhill shoulder and hip forward, flattening your outside ski. If your hands are always up, level and in front of you, you will hardly have to move your downhill hand to plant your pole in the right place at the right time (LeMaster, 2011).

Problem statement: the capacity of combining/recombining complex mental images is determined by specific proprioceptive and kinaesthetic information processing (Grosu, 2012). We selected several drills that we applied to the experimental group within the physical training program. Hand on the hip and hand in the air: this drill is excellent for sensing the moment for edge release and initiating the subsequent turn. To perform this drill, place your downhill hand on your downhill hand on your downhill hip and raise your uphill hand in front of your uphill shoulder. Repeat this movement several times. We also present other drills, such as carved turn with hands on knees; long leg, short leg; advance railroad track; traverse edge change; outside pole drag: to perform this drill, assume an engaged stance and extend your arms to the sides, holding your poles like swords. In the fall line, reach over the outside ski and etch an arc in the snow with your pole tip and your skis (Fellows, 2011).

To help develop solid, quiet arms, this exercise is effective: tie a 5 -foot $(1.5 \mathrm{~m})$ piece of string into a loop. Put your hands in the loop, hold them far enough apart to keep the loop snug, and go skiing. The loop helps keep your hands where you want them and prevents you from dropping one or the other. A few runs like this every now and then will significantly improve your arm discipline and your lateral balance.

In skiing, to improve your lateral stability at the control point, you must plant your pole at the end of the turn, not at the beginning of the next one. Get the pole ready early. Good skiers have their pole ready to plant when they are halfway through the turn. And when you plant it, plant it in the right place. Extend your arm well away from your body, and put the tip of the pole in the snow ahead of your hand (LeMaster, 2011). 


\section{Methodology}

Purpose of study: The elaboration of training methods that include, in the teaching process, elements of psychology, mental imagery and feed-back regarding the conscious control of neurophysiological correlates involved in the conception of representations or of proprioceptive and complex and complex movements. The purpose is to improve skills, coordination, trust, calm, and focus. It is more than daydreaming: the active study of an image or of a series of images and the use of all body senses - the athlete must fell as if he/she were on the move.

In order to determine the hand-eye coordination capacity in alpine skiing, we tested it by using a device called Computer-assisted system for assessment in transport and labour psychology, 04/2007 version, created by Management Design SRL lasi, by Professor Hãvârneanu C. (2007), at Psitest Cabinet. According to the scheme of integrated functional blocks, the methodological core proposed provides the possibility of obtaining indicators of information, execution and self-regulation capacity indicators of safe behaviour (according to the term "vigilance" as understood by Bonnardel (Hãvârneanu, 2007).

Methods: The literature on mental training uses terms such as "mental rehearsal", "mental practice", "visual-motor behavioural rehearsal", "mental practice (execution)", "disguised, hidden rehearsal", "hidden practice", "visualization", "cognitive rehearsal", "imaginary practice", "rehearsal in representation", "introspective rehearsal", "implicit practice", "ideomotor training", "mental imagination" (Grosu, 1999).

After applying the mental training techniques on the experimental group, significant alterations were found in certain parameters of hand-eye coordination. We considered that during competitions a skier is like a driver in a vehicle, in terms of attention (concentration and distribution) and hand-eye coordination.

This test assesses aspects concerning the perception (speed and accuracy) and the operational efficiency of thought. Information on reactivity are completed by examining the simple reaction time (basic reactivity), (Hãvârneanu, 2011). Among the indicators recorded through this test, it is worth noting the following: VP - perception speed $=$ number of omissions, $E P-$ perception accuracy $=$ number of errors, EX - focused attention = correct answers $/ 150+$ wrong answers.

From a technical perspective, we asked the athletes within the mental training program to consider the following essential aspects: 1 . Ski straight down a cat track. Do not think about your feet but feel how your arms and hands are hanging. Note how claustrophobic it feels (or should feel) to hold your arms pressed against your sides. Then note how awkward it feels to hold your arms wide, as if you were hugging a redwood. Try to establish a comfortable position between these two extremes. Feel the way your arm rotates at the shoulder and bends slightly at the elbow and feel the slight flick of the wrist that comes at the end of pole swing. 2. Try swinging your arms smoothly and quickly, then swing them slowly. Approximate your timing for short turns and long turns. Feel the way your arms and hands move the same distance but at a faster or slower rate (Elling, 2003).

From a technical perspective, we asked the athletes within the mental training program to consider the following essential aspects: positive pole-planting before impact, use your left wrist to swing the pole diagonally forwards into an angled position; using the O-frame posture you have been practising, angle the pole for maximum strength on impact; begin moving your right wrist, ready for the next plant, and maintain your O-frame arm position; try to angle the pole so that the basket is ahead of your hand (this will increase the power of impact); on impact, keep driving the wrist forwards and downwards to help maintain the shape of the O-frame posture; work the left-hand wrist to manoeuvre the pole into the correct angle for the next plant (Warren, 2006). 


\section{Findings}

We calculated a t test for dependent samples for VP, EP and EX posttest, to assess whether the intervention produced any modifications.

Table 1. Descriptive statistics

\begin{tabular}{llllll}
\hline & Group & $\mathrm{N}$ & Mean & $\begin{array}{l}\text { Std. } \\
\text { Deviation }\end{array}$ & $\begin{array}{l}\text { Std. Error } \\
\text { Mean }\end{array}$ \\
\hline \multirow{3}{*}{ VP_posttest } & control & 24 & 10 & 6.04332 & 1.23359 \\
& experimental & 24 & 4.0417 & 3.85023 & 0.78593 \\
EP_posttest & control & 24 & 18.5417 & 9.14606 & 1.86693 \\
& experimental & 24 & 9.8333 & 4.40026 & 0.8982 \\
EX_posttest & control & 24 & 0.8625 & 0.07897 & 0.01612 \\
\hline
\end{tabular}

Tabel 2. T test for independent samples - VP, EP and EX

\begin{tabular}{|c|c|c|c|c|c|c|c|c|}
\hline & & \multicolumn{2}{|c|}{$\begin{array}{l}\text { Levene's Test for } \\
\text { Equality of Variances }\end{array}$} & \multicolumn{5}{|c|}{ t-test for Equality of Means } \\
\hline & & $\mathrm{F}$ & Sig. & $\mathrm{t}$ & df & $\begin{array}{l}\text { Sig. }(2- \\
\text { tailed) }\end{array}$ & $\begin{array}{l}\text { Mean } \\
\text { Difference }\end{array}$ & $\begin{array}{l}\text { Std. Error } \\
\text { Difference }\end{array}$ \\
\hline \multirow{2}{*}{ VP_posttest } & EVA & 1.595 & 0.213 & 4.074 & 46 & 0 & 5.95833 & 1.46267 \\
\hline & EVNA & & & 4.074 & 39.03 & 0 & 5.95833 & 1.46267 \\
\hline \multirow{2}{*}{ EP_posttest } & EVA & 19.243 & 0 & 4.203 & 46 & 0 & 8.70833 & 2.07176 \\
\hline & EVNA & & & 4.203 & 33.106 & 0 & 8.70833 & 2.07176 \\
\hline \multirow{2}{*}{ EX_posttest } & EVA & 4.846 & 0.033 & -3.279 & 46 & 0.002 & -0.06458 & 0.0197 \\
\hline & EVNA & & & -3.279 & 41.24 & 0.002 & -0.06458 & 0.0197 \\
\hline
\end{tabular}

*EVA-Equal variances assumed; **EVNA-Equal variances not assumed

We found statistically significant correlations $-p=.000<0.05-$ for posttest measurements for VP, EP and EX.

Findings indicate the emergence of a statistically significant modification following the intervention, for VP, EP and EX, $p=.000<0.05$ and $p=.001<0.05$.

\section{Conclusion and recommendations}

Findings indicate the emergence of a modification in both the control and the experimental group, as follows. For $\mathrm{VP}$ before the intervention, $M=15.333, S D=8.90$, while afterwards $M=7.020$ and $S D=$ 5.84. For $E P$ before the intervention, $M=19.93$ and $S D=14.87$, while afterwards $M=14.18$ and $S D=$ 8.35. Finally, for $E X$ before the intervention $M=.82, S D=.103$ and after it $M=.89, S D=.074$. The results are statistically significant following the intervention for scores in VP, EX and EP $t(47)=8.456, t$ (47) $=7.089 p=.000<0.05$ and $t(47)=3.415 p=.001<0.05$.

Skiers trying to increase their pole-plant strength often make the mistake of swinging their arms up and down in an attempt to increase the power of the plant.

To develop the strength of your pole, plant correctly, work on the following techniques (Warren, 2006). They are designed to stabilize your arms and improve the power of your pole-plant. 
It is worth adding that the purpose of mental representation is to use mental imagery in order to reproduce mentally the sensations and feelings experienced while performing a skill.

\section{Special acknowledgment}

We are very grateful to the skiers and ski trainers who participated in our experiment, especially athletes within the following Clubs: CS Baia - Sprie (MM), SGH - CS Gheorgheni (HR). We would also like to thank the students of the Faculty of PE and Sports (specialized in ski) of the Babes - Bolyai University, who helped us during the experiment, as well as to the skiers of the other ski clubs in Romania: CS Sinaia (PH), CS Predeal (BV), C Crazy - Bike Sibiu (SB), C Piatra - Neamt (NT), CS Miercurea-Ciuc (HR).

\section{References}

LeMaster, R. (2010). Ultimate skiing. (pp. 108-109, 142-143, 150). Master the techniques of great skiing, United States: Human kinetics. Champaign, iL 61825-5076-800-747-4457.

Grosu, E.F. (2012). Tehnici de antrenament mental. (3rd edition). (pp. 9). Cluj-Napoca: GMI Press. ISBN 978-973 